\title{
Heterogeneous oxidation of cyclohexanone catalyzed by TS-1: Combined experimental and DFT studies
}

\author{
Changjiu Xia ${ }^{\mathrm{a}, \mathrm{b}}$, Long Ju ${ }^{\mathrm{b}}$, Yi Zhao ${ }^{\mathrm{b}}$, Hongyi Xu ${ }^{\mathrm{a}}$, Bin Zhu ${ }^{\mathrm{b}}$, Feifei Gao ${ }^{\mathrm{a}}$, Min Lin ${ }^{\mathrm{b}, *}$, Zhenyu Dai ${ }^{\mathrm{b}}$, \\ Xiaodong Zou ${ }^{\text {a,\# }, \text { Xingtian Shu }}{ }^{\mathrm{b}}$ \\ a Department of Materials and Environmental Chemistry, Stockholm University, SE-106 91 Stockholm, Sweden \\ b State Key Laboratory of Catalytic Materials and Reaction Engineering, Research Institute of Petroleum Processing, SINOPEC, Beijing100083, China
}

\section{A R T I C L E I N F O}

\section{Article history:}

Received 26 February 2015

Accepted 2 April 2015

Published 20 June 2015

\section{Keywords:}

Titanium silicate

Zeolite

Cyclohexanone

Baeyer-Villiger oxidation

Hydrogen peroxide

Lewis acid catalysis

\begin{abstract}
A B S T R A C T
The reaction mechanism of the oxidation of cyclohexanone catalyzed by titanium silicate zeolite TS-1 using aqueous $\mathrm{H}_{2} \mathrm{O}_{2}$ as the oxidant was investigated by combining density function theory (DFT) calculations with experimental studies. DFT calculations showed that $\mathrm{H}_{2} \mathrm{O}_{2}$ was adsorbed and activated at the tetrahedral Ti sites. By taking into account the adsorption energy, molecular size, steric hindrance and structural information, a reaction mechanism of Baeyer-Villiger oxidation catalyzed by TS- 1 that involves the activation of $\mathrm{H}_{2} \mathrm{O}_{2}$ was proposed. Experimental studies showed that the major products of cyclohexanone oxidation by $\mathrm{H}_{2} \mathrm{O}_{2}$ catalyzed by a hollow TS- 1 zeolite were $\varepsilon$-carprolactone, 6-hydroxyhexanoic acid, and adipic acid. These products were analyzed by GC-MS and were in good agreement with the proposed mechanism. Our studies showed that the reaction mechanism on TS-1 zeolite was different from that on Sn-beta zeolite.
\end{abstract}

(C) 2015, Dalian Institute of Chemical Physics, Chinese Academy of Sciences. Published by Elsevier B.V. All rights reserved.

\section{Introduction}

Baeyer-Villiger (BV) oxidation is an important organic reaction by which esters or lactones are produced from ketones. Esters and lactones are important organic intermediates in chemical processes [1-6]. For example, $\varepsilon$-carprolactone, which is widely used to synthesize polymers, is produced from cyclohexanone. Traditionally, peracids, e.g. perbenzoic acid, $m$-chloroperbenzoic acid and trifluoroperacetic acid, are used as oxidizing agents in BV oxidation reactions [7-12]. Although the use of a peracid can lead to very high ketone conversion and fast product transformation, it is desirable to find cheaper and less polluting routes for BV oxidation for the preparation of lactones on the commercial scale [13-19].

Aqueous $\mathrm{H}_{2} \mathrm{O}_{2}$ solution (usually 30 wt $\%-50 \mathrm{wt} \%$ ), which is environmentally-friendly, cheap and easy to handle, has been introduced as the oxidant to replace hazardous peracids. One drawback is that $\mathrm{H}_{2} \mathrm{O}_{2}$ is less effective than peracids in attacking nucleophiles in order to activate the carbonyl group of ketones. In previous works, much effort was devoted to develop both homogeneous and heterogeneous catalysts in order to improve the performance of $\mathrm{BV}$ oxidation of cyclohexanone [20-24].

Heterogeneous catalysts have an important advantage over homogeneous ones for industrial applications because it is easier to separate the catalyst from the reactants and products

\footnotetext{
* Corresponding author. Tel/Fax: +86-10-82368801; E-mail: minlin@tom.com

\# Corresponding author. Tel: +46-8162389; Fax: +46-8152187; E-mail: xzou@mmk.su.se

This work was supported by the National Basic Research Program of China (973 Program, 2006CB202508), China Petrochemical Corporation (SINOPEC Group 20673054), Swedish Research Council (VR), and Knut and Alice Wallenberg Foundation (Catalysis in Selective Organic Synthesis). DOI: 10.1016/S1872-2067(15)60859-2 | http://www.sciencedirect.com/science/journal/18722067 | Chin. J. Catal., Vol. 36, No. 6, June 2015
} 
[25-28]. There are two possible strategies to accelerate the heterogeneous BV oxidation of cyclohexanone using aqueous $\mathrm{H}_{2} \mathrm{O}_{2}$ solution (especially $30 \mathrm{wt} \%$ ): (1) activate the carbonyl group of cyclohexanone with a Lewis acid catalyst to make the carbonyl $\mathrm{C}$ atom more easily attacked by the $\mathrm{H}_{2} \mathrm{O}_{2}$ molecule [29-32]; (2) increase the nucleophilicity of $\mathrm{H}_{2} \mathrm{O}_{2}$ molecules by forming more nucleophilic $\mathrm{M}-\mathrm{OOH}$ species (M represents transition metal ions, which can accept the lone electron pairs of $\mathrm{O}$ atoms in the $\mathrm{H}_{2} \mathrm{O}_{2}$ molecules by employing their empty $3 d$ orbitals) [33-38]. One excellent example is the Sn-beta zeolite catalyzed BV oxidation of cyclohexanone reported by Corma and coworkers, in which the lactone selectivity was close to $100 \%$ [22]. The Sn-beta zeolite has unique Lewis acid properties that make the carbonyl group more reactive to be attacked by $\mathrm{H}_{2} \mathrm{O}_{2}$ molecules. The Lewis acid site, especially in the form of $\mathrm{Sn}(\mathrm{SiO})_{3} \mathrm{OH}$, can accept the lone electron pair from the cyclohexanone molecule, causing the electron cloud of the $\mathrm{O}$ atom in the carbonyl group to move towards the tetrahedral $\mathrm{Sn}$ atoms. As a consequence, the $\mathrm{C}$ atom in the carbonyl group becomes more easily attacked by $\mathrm{H}_{2} \mathrm{O}_{2}$ molecules.

In addition, it is well known that Ti-containing zeolites (in particular TS-1 zeolite) are good candidates to enhance nucleophilic attack by $\mathrm{H}_{2} \mathrm{O}_{2}$ molecules under moderate conditions, since the Ti atoms can accept the lone electron pairs of $\mathrm{H}_{2} \mathrm{O}_{2}$ by using its empty $3 d$ orbitals to form a Ti-OOH species [39-42]. The Ti-OOH species is much more reactive than $\mathrm{H}_{2} \mathrm{O}_{2}$, so nucleophilic attack of the $\mathrm{C}$ atom of the carbonyl group in cyclohexanone can be enhanced. Previous reports on BV oxidation of cyclohexanone catalyzed by TS-1 zeolite showed that many different products were formed in the absence of an organic solvent because $\varepsilon$-carprolactone was not stable and the $\mathrm{Ti}-\mathrm{OOH}$ species could promote both the main BV oxidation and the side reactions simultaneously. Therefore, side products were obtained by consecutive ring opening and deep oxidation reactions.

There is no theoretical study of the mechanism of BV oxidation catalyzed by TS- 1 zeolites using $\mathrm{H}_{2} \mathrm{O}_{2}$ as the oxidant. Here, we present a mechanistic study of the heterogeneous oxidation of cyclohexanone catalyzed by TS- 1 zeolite using $\mathrm{H}_{2} \mathrm{O}_{2}$ as the oxidant based on density functional theory (DFT). We also performed catalytic experiments using a hollow TS-1 (HTS-1) zeolite [43-45] as the catalyst for the heterogeneous oxidation of cyclohexanone, and showed that the results support the proposed reaction mechanism.

\section{Experimental}

\subsection{Synthesis of HTS-1 zeolite and catalytic experiments of the heterogeneous oxidation of cyclohexanone}

First, TS-1 zeolite was prepared according to a conventional method [41]. Tetraethyl orthosilicate and titanium butoxide were added dropwise to an aqueous tetrapropylammonium hydroxide (TPAOH) solution under continuous stirring. The molar ratio of $\mathrm{TiO}_{2}: \mathrm{SiO}_{2}: \mathrm{TPAOH}: \mathrm{H}_{2} \mathrm{O}$ was 0.03:1.00:0.15:22.0. The mixture was heated at $80^{\circ} \mathrm{C}$ for $4 \mathrm{~h}$ to remove the alcohols, then transferred into a Teflon-lined stainless steel autoclave, and heated at $170{ }^{\circ} \mathrm{C}$ for $72 \mathrm{~h}$ under autogeneous pressure. The product, TS-1 zeolite, was collected by filtration, washed with water, and calcined at $550{ }^{\circ} \mathrm{C}$ in air for $6 \mathrm{~h}$.

HTS-1 zeolite was synthesized from calcined TS- 1 zeolite in an aqueous TPAOH solution at $170{ }^{\circ} \mathrm{C}$ for $24 \mathrm{~h}$ according to the literature $[43,45]$. X-ray powder diffraction (XRD) results showed well-crystallized TS-1 and HTS-1 powders with the MFI structure (Fig. S1). Transmission electron microscopy (TEM) images showed uniformly sized TS- 1 and HTS-1 particles with mesopores present in the HTS-1 particles (Fig. S2). $\mathrm{N}_{2}$ adsorption isotherms showed that HTS-1 contained mesopores (Fig. S3). The BET surface areas and pore volumes of TS-1 and HTS-1 are given in Table S1.

The heterogeneous oxidation reaction of cyclohexanone using $\mathrm{H}_{2} \mathrm{O}_{2}$ as the oxidant was carried out in a $100-\mathrm{ml}$ three-necked flask under magnetic stirring. A mixture of the HTS-1 zeolite catalyst (5 wt $\%$ ) and $0.01 \mathrm{~mol}$ cyclohexanone, either without an organic solvent or in the presence of an organic solvent (acetone or methanol), was added into the flask and heated to the reaction temperature. Then $\mathrm{H}_{2} \mathrm{O}_{2}$ solution (0.01 mol, $30 \mathrm{wt} \%)$ was injected into the flask. After several hours ( 4 or $8 \mathrm{~h}$ ), a small amount of the mixture was extracted from the flask and analyzed by an Agilent 6890 gas chromatograph with a 3-m HP-5 column and hydrogen flame ionization detector. The main products and side products were confirmed by gas chromatography-mass spectrometry (GC-MS) on an Agilent 5977A series GC/MSD system.

\subsection{Molecular models and computational methods}

TS- 1 has the MFI zeolite topology with the unit cell parameters $a=20.13 \AA, b=19.95 \AA, c=13.42 \AA$ [1]. There are 12 symmetry-independent and a total of 96 T-atoms in a unit cell. It has a three dimensional 10-ring channel system with straight channels along the [010) direction and sinusoidal channels perpendicular to the straight channels. The highest Ti content in the TS-1 framework was $2.5 \mathrm{~mol} \%$ ( $\mathrm{Si} / \mathrm{Ti}=39$ ), i.e., on average two $\mathrm{Si}$ atoms in each unit cell were substituted by Ti atoms. To understand the adsorption and activation of cyclohexanone and $\mathrm{H}_{2} \mathrm{O}_{2}$ at the active sites of TS- 1 zeolite, a Ti(OSiH$)_{4}$ cluster model was used [1-3], as shown in Fig. 1. The cluster was cut from the TS-1 zeolite structure and contains one Ti atom at the $\mathrm{T} 7$ site connected to four $-\mathrm{O}-\mathrm{SiH}_{3}$ fragments. The direction of each $\mathrm{H}$ atom in the cluster was set to be the same as that of the corresponding 0 atom in the TS- 1 zeolite framework in order to use the actual structure for the active site. The adsorption and activation of cyclohexanone and $\mathrm{H}_{2} \mathrm{O}_{2}$ on the active Ti site were calculated by the Adsorption Locator module in the MS software. The transition states were analyzed by using the effective core potential method and the DMol3 module in the MS software which uses the LST/QST protocol and employs the GGA/PW91 technique. Furthermore, the $\mathrm{Ti}\left(\mathrm{OSiH}_{3}\right)_{3} \mathrm{OH}$ cluster was considered as the active site for BV catalytic oxidation in TS-1 zeolite [39]. Its geometry optimization of the reaction pathway was performed using the B3PW91 method in order to investigate the mechanism of the catalytic oxidation of cyclohexanone. 


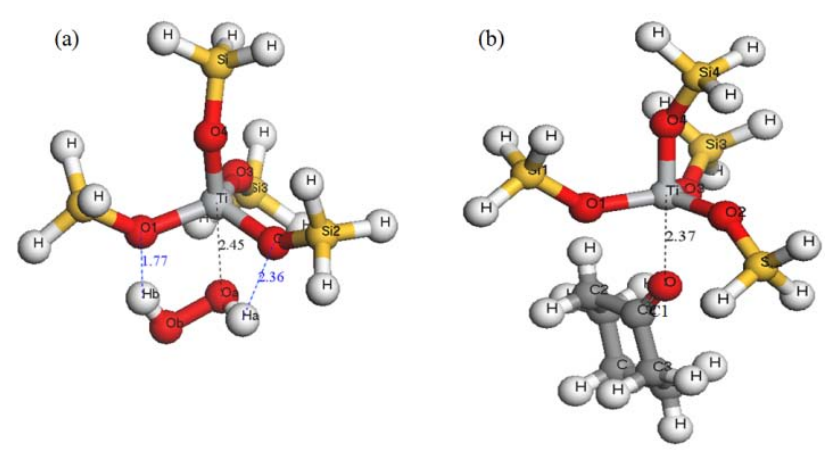

Fig. 1. Models of $\mathrm{H}_{2} \mathrm{O}_{2}$ (a) and cyclohexanone (b) adsorbed on the $\mathrm{Ti}\left(\mathrm{OSiH}_{3}\right)_{4}$ cluster. Some Ti $\cdots \mathrm{O}$ and $\mathrm{O} \cdots \mathrm{H}$ distances are given.

\section{Results and discussion}

3.1. Study of the reaction mechanism of the heterogeneous oxidation of cyclohexanone catalyzed by TS-1

\subsubsection{Competitive adsorption and activation of cyclohexanone and $\mathrm{H}_{2} \mathrm{O}_{2}$}

Without taking steric hindrance effect into account, the calculated adsorption energy of the unconstrained $\left.\mathrm{Ti}_{(\mathrm{OSiH}}\right)_{4}$ cluster is $-135.1 \mathrm{~kJ} / \mathrm{mol}$ for cyclohexanone and $-384.6 \mathrm{~kJ} / \mathrm{mol}$ for $\mathrm{H}_{2} \mathrm{O}_{2}$. The $\mathrm{Ti} \cdots \mathrm{O}$ distance is $2.37 \AA$ for cyclohexanone and $2.45 \AA$ for $\mathrm{H}_{2} \mathrm{O}_{2}$. When a $\mathrm{H}_{2} \mathrm{O}_{2}$ molecule approaches the active site, there is an interaction between the lowest unoccupied molecular orbital (LUMO) of TS-1 and the highest occupied molecular orbital (HOMO) of the $\mathrm{O}$ atoms in the $\mathrm{H}_{2} \mathrm{O}_{2}$ molecules $\left(\mathrm{Ti} \cdots \mathrm{O}_{\mathrm{a}}=2.45 \AA\right.$ ) (Fig. 1(a) and Fig. S6). Meanwhile, the $\mathrm{H}$ atoms in the $\mathrm{H}_{2} \mathrm{O}_{2}$ molecule can interact with the $\mathrm{O}$ atoms around the tetrahedral Ti species by forming intermolecular hydrogen bonds between $\mathrm{O}$ and $\mathrm{H}$ atoms $\left(\mathrm{O}_{1} \cdots \mathrm{H}_{\mathrm{b}}=1.77 \AA\right.$ and $\mathrm{O}_{2} \cdots \mathrm{H}_{\mathrm{a}}=$ $2.36 \AA$ ) to minimize the adsorption energy. On the other hand, the cyclohexanone molecule has a three dimensional non-planar structure, while the $\mathrm{H}_{2} \mathrm{O}_{2}$ molecule has a two dimensional non-linear structure. This means that the steric hindrance of cyclohexanone inside the channel of TS- 1 zeolite is stronger than that of $\mathrm{H}_{2} \mathrm{O}_{2}$ so that $\mathrm{H}_{2} \mathrm{O}_{2}$ molecules are more easily adsorbed at the tetrahedral $\mathrm{Ti}$ active sites than cyclohexanone molecules. The adsorption energy is thus lower for $\mathrm{H}_{2} \mathrm{O}_{2}$ than for cyclohexanone.

It is well known that TS-1 zeolite is an excellent catalyst to improve the nucleophilic attack capability of $\mathrm{H}_{2} \mathrm{O}_{2}$ in many catalytically oxidative reactions [1,2]. When a $\mathrm{H}_{2} \mathrm{O}_{2}$ molecule is adsorbed on the tetrahedral Ti site (Fig. 1(a)), the charges on the $\mathrm{O}_{\mathrm{a}}$ and $\mathrm{O}_{\mathrm{b}}$ atoms are -0.46 and -0.48 , respectively, which are more negative than those in the original $\mathrm{H}_{2} \mathrm{O}_{2}$ molecules (about -0.43), as given in Table 1 . This indicates that the $\mathrm{H}_{2} \mathrm{O}_{2}$ molecules are activated, followed by formation of a $\mathrm{Ti}-\mathrm{OOH}$ species.

When a cyclohexanone molecule is adsorbed at the active site of the $\left.\mathrm{Ti}_{(\mathrm{OSiH}}\right)_{4}$ cluster (Fig. 1(b)), it is activated by the donor-acceptor interaction of the lone electron pair between the LUMO of Ti active sites in the $\mathrm{Ti}\left(\mathrm{OSiH}_{3}\right)_{4}$ clusters and the
Table 1

Charge and charge difference of the $\mathrm{Ti}\left(\mathrm{OSiH}_{3}\right)_{4}$ cluster and a $\mathrm{H}_{2} \mathrm{O}_{2}$ molecule before and after $\mathrm{H}_{2} \mathrm{O}_{2}$ adsorption.

\begin{tabular}{|c|c|c|c|c|}
\hline Substance & Atoms & $\begin{array}{c}\text { Before } \mathrm{H}_{2} \mathrm{O}_{2} \\
\text { adsorption }\end{array}$ & $\begin{array}{l}\text { After } \mathrm{H}_{2} \mathrm{O}_{2} \\
\text { adsorption }\end{array}$ & $\begin{array}{c}\text { Charge } \\
\text { difference }\end{array}$ \\
\hline \multirow{5}{*}{$\begin{array}{l}\mathrm{Ti}\left(\mathrm{OSiH}_{3}\right)_{4} \\
\text { cluster }\end{array}$} & $\mathrm{Ti}$ & 1.69 & 1.60 & -0.09 \\
\hline & $0^{1}$ & -0.85 & -0.90 & -0.05 \\
\hline & $\mathrm{O}^{2}$ & -0.85 & -0.86 & -0.01 \\
\hline & $\mathrm{O}^{3}$ & -0.85 & -0.83 & 0.02 \\
\hline & $\mathrm{O}^{4}$ & -0.85 & -0.84 & 0.01 \\
\hline \multirow[t]{4}{*}{$\mathrm{H}_{2} \mathrm{O}_{2}$} & $\mathrm{O}_{\mathrm{a}}$ & -0.43 & -0.46 & -0.03 \\
\hline & $\mathrm{O}_{\mathrm{b}}$ & -0.43 & -0.48 & -0.05 \\
\hline & $\mathrm{H}_{\mathrm{a}}$ & 0.43 & 0.41 & -0.02 \\
\hline & $\mathrm{H}_{\mathrm{b}}$ & 0.43 & 0.47 & 0.04 \\
\hline
\end{tabular}

HOMO of $\mathrm{C}=0$ groups of the cyclohexanone molecule (Fig. S6). The charge differences of the atoms in the $\mathrm{Ti}\left(\mathrm{OSiH}_{3}\right)_{4}$ cluster and cyclohexanone before and after chemical adsorption are listed in Table 2 . The positive charge of $\mathrm{C}_{1}$ atom after chemical adsorption $(\sim 0.48)$ is higher than that before the adsorption process $(\sim 0.41)$ in the cyclohexanone molecule. In the meantime, the $\mathrm{C}=\mathrm{O}$ bond length in the model after the adsorption is $1.23 \AA$, while that in an isolated cyclohexanone molecule is 1.21 $\AA$. These data indicate that the $\mathrm{C}=0$ double bond becomes slightly weaker, and the cyclohexanone molecule is adsorbed at the active site. This suggests that the $C_{1}$ atom of the carbonyl group is more reactive and will more easily accept the nucleophilic attack of $\mathrm{H}_{2} \mathrm{O}_{2}$ molecules compared to those in the original cyclohexanone molecule. Therefore, it was confirmed that both $\mathrm{H}_{2} \mathrm{O}_{2}$ and cyclohexanone molecules are adsorbed and activated at the tetrahedral Ti active sites by the donor-acceptor interaction between the Ti species in TS- 1 zeolite and 0 atoms in $\mathrm{H}_{2} \mathrm{O}_{2}\left(\mathrm{O}_{\mathrm{a}}\right)$ and cyclohexanone $\left(\mathrm{O}_{\mathrm{c}}\right)$ molecules.

\subsubsection{Reaction mechanism of Baeyer-Villiger oxidation of cyclohexanone catalyzed by TS-1 zeolite}

By taking into consideration the calculated geometric structures, transition states and energy profiles, a reaction mechanism of TS-1 catalyzed BV oxidation is shown in Fig. 2. At the initial stage of the reaction, a $\mathrm{Ti}-\mathrm{OH}$ group is formed through the hydrolysis of a Ti-O-Si bond in TS-1 zeolite [52]. A $\mathrm{H}_{2} \mathrm{O}_{2}$ molecule is then adsorbed on TS- 1 by hydrogen bonds between $\mathrm{H}_{a}, \mathrm{Hb}_{b}$ of the $\mathrm{H}_{2} \mathrm{O}_{2}$ molecule and $\mathrm{O}^{4}, \mathrm{O}^{3}$ that are con-

Table 2

Charge and charge difference of the $\mathrm{Ti}\left(\mathrm{OSiH}_{3}\right)_{4}$ cluster and a cyclohexanone molecule before and after cyclohexanone adsorption.

\begin{tabular}{lcccc}
\hline Substance & Atoms & $\begin{array}{c}\text { Before } \\
\text { cyclohexanone } \\
\text { adsorption }\end{array}$ & $\begin{array}{c}\text { After } \\
\text { cyclohexanone } \\
\text { adsorption }\end{array}$ & $\begin{array}{c}\text { Charge } \\
\text { difference }\end{array}$ \\
\hline Ti(OSiH \\
cluster $)_{4}$ & $\mathrm{Ti}$ & 1.69 & 1.56 & -0.13 \\
& $\mathrm{O}^{1}$ & -0.85 & -0.83 & 0.02 \\
& $\mathrm{O}^{2}$ & -0.85 & -0.83 & 0.02 \\
& $\mathrm{O}^{3}$ & -0.85 & -0.84 & 0.01 \\
Cyclohexanone & $\mathrm{O}^{4}$ & -0.85 & -0.83 & 0.02 \\
& $\mathrm{O}_{\mathrm{c}}$ & -0.39 & -0.40 & -0.01 \\
& $\mathrm{C}_{1}$ & 0.41 & 0.48 & 0.07 \\
& $\mathrm{C}_{2}$ & -0.38 & -0.55 & -0.17 \\
& $\mathrm{C}_{3}$ & -0.38 & -0.53 & -0.15 \\
\hline
\end{tabular}


nected to the active Ti site (see R1 in Fig. 2) to minimize the total energy of the adsorption system. Then, the $\mathrm{Ti}-\mathrm{O}_{\mathrm{a}}$ bonds become shorter because of the strong interaction of acceptor-donator with the lone electron pairs, while the $\mathrm{Ti}-\mathrm{O}^{4}$ and $\mathrm{O}_{\mathrm{a}}-\mathrm{H}_{\mathrm{a}}$ bonds are broken (see TS1 in Fig. 2). The calculated activation energy, which is defined as the energy difference between reactants (R1) and transition state (TS1), for this process is $58.0 \mathrm{~kJ} / \mathrm{mol}$ because the energies required to break the
Ti- $\mathrm{O}^{4}$ and $\mathrm{H}_{\mathrm{a}}-\mathrm{O}_{\mathrm{a}}$ bonds are high. After one $\mathrm{H}_{2} \mathrm{O}$ molecule has been removed, one $\mathrm{Ti}-\mathrm{O}_{\mathrm{a}}-\mathrm{O}_{\mathrm{b}}-\mathrm{H}_{\mathrm{b}}$ group is produced (see P1 in Fig. 2).

In step 2, a cyclohexanone molecule is adsorbed by forming hydrogen bonds between $\mathrm{H}_{\mathrm{b}}$ in the $\mathrm{Ti}-\mathrm{O}_{\mathrm{a}}-\mathrm{O}_{\mathrm{b}}-\mathrm{H}_{\mathrm{b}}$ group and $\mathrm{O}_{\mathrm{c}}$ in the carbonyl group of cyclohexanone (P2 in Fig. 2). The $\mathrm{Ob}_{\mathrm{b}}$ atom in the $\mathrm{Ti}-\mathrm{O}_{\mathrm{a}}-\mathrm{O}_{\mathrm{b}}-\mathrm{H}_{\mathrm{b}}$ group, which has a stronger negative charge than those in the $\mathrm{H}_{2} \mathrm{O}_{2}$ molecule, can make a nucleo-
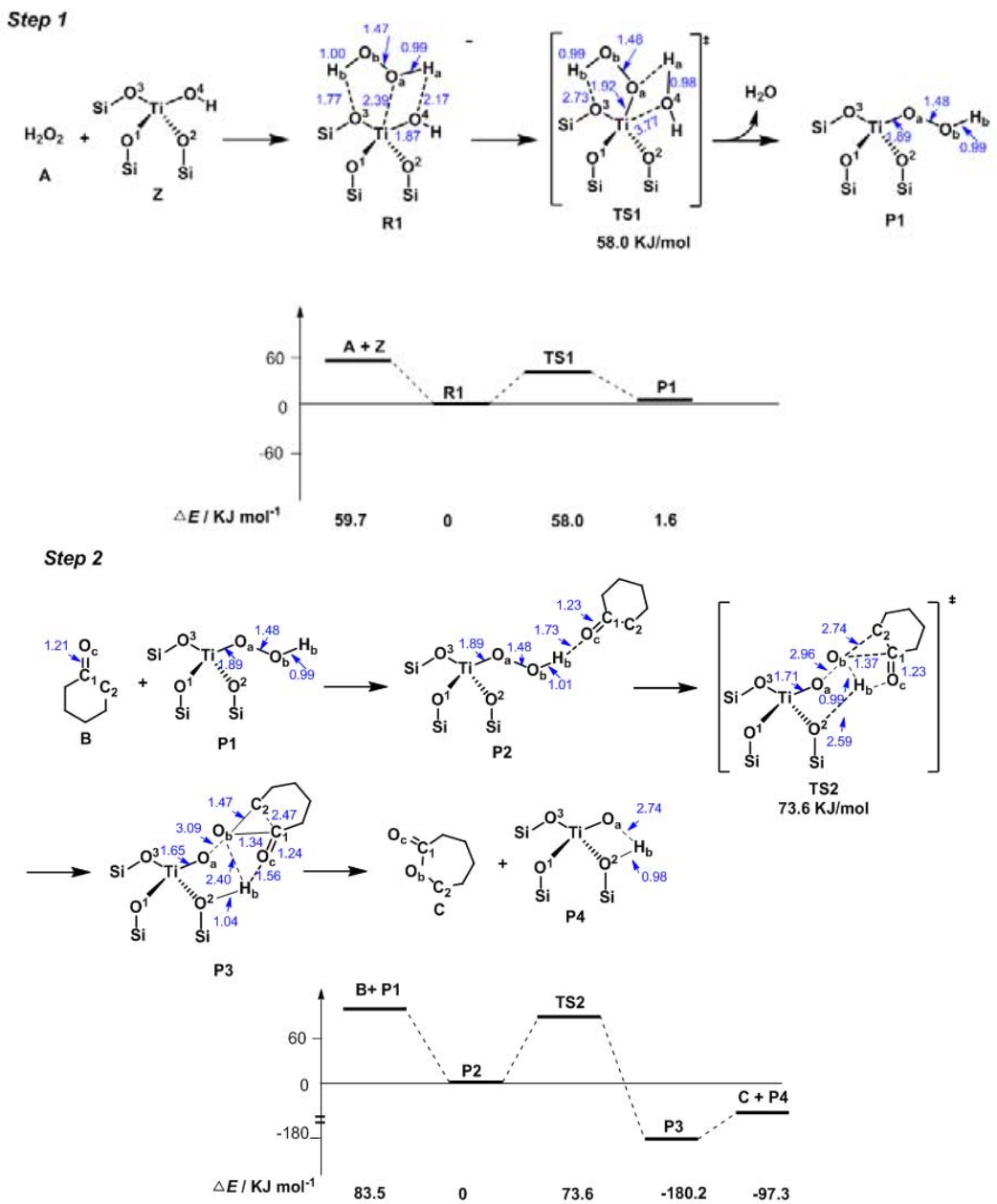

Step 3
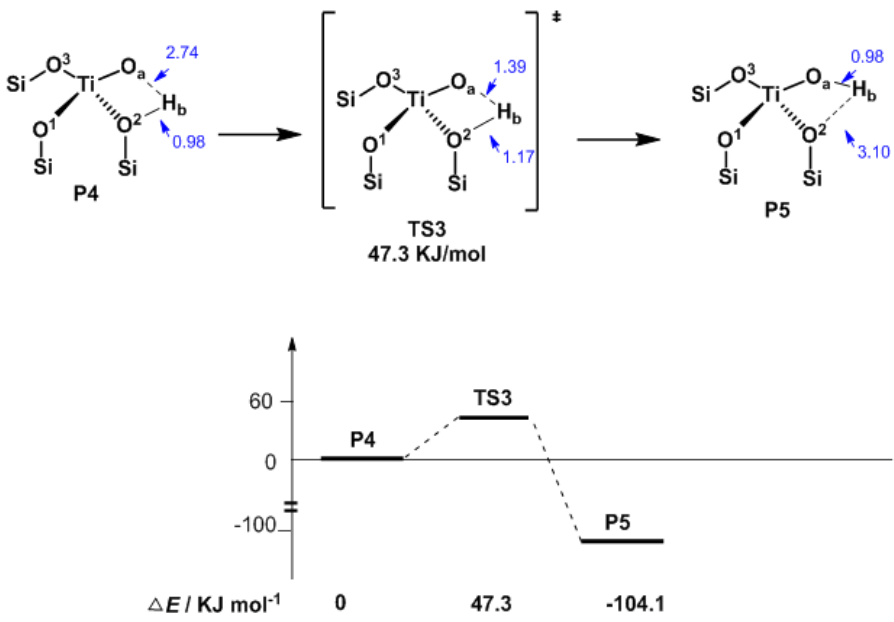

Fig. 2. Reaction pathway and calculated energy profiles of TS-1 zeolite catalyzed cyclohexanone BV oxidation. ‡ represents the transition state. 
philic attack on the $\mathrm{C}_{1}$ atom in the carbonyl group and its neighboring $\mathrm{C}_{2}$ atom in the cyclohexanone to form the Criegee intermediate (TS2 in Fig. 2). The $\mathrm{O}_{a}-\mathrm{O}_{b}$ and $\mathrm{C}_{1}-\mathrm{C}_{2}$ bonds break, a new $\mathrm{C}_{1}-\mathrm{O}_{\mathrm{b}}$ bond forms, and the $\mathrm{Ti}-\mathrm{O}_{\mathrm{a}}$ bond becomes shorter. The activation energy for this process is very high (73.6 $\mathrm{kJ} / \mathrm{mol}$ ), which may be attributed to the breaking of the strong $\mathrm{O}_{\mathrm{a}}-\mathrm{O}_{\mathrm{b}}$ covalent bond. Then the $\mathrm{O}_{\mathrm{b}}-\mathrm{H}_{\mathrm{b}}$ bond breaks, and a $\mathrm{C}_{1}-\mathrm{O}_{\mathrm{b}}$ bond forms (P3 in Fig. 2). We noticed that the $\mathrm{C}_{1}=\mathrm{O}_{\mathrm{c}}$ bond still remains with a bond length of $1.24 \AA$. Finally, one $\varepsilon$-carprolactone molecule and a P4 complex are generated (see C in Fig. 2).

In step 3, the $\mathrm{Ti}\left(\mathrm{OSiH}_{3}\right)_{3} \mathrm{OH}$ active species (see $\mathrm{P} 5$ in Fig. 2) is regenerated from $\mathrm{P} 4$ by the cleavage of the $\mathrm{O}^{2}-\mathrm{H}_{b}$ bond and the formation of the $\mathrm{O}_{a}-\mathrm{H}_{b}$ bond, and then a BV oxidation cycle is completed. The activation energy barrier for step 3 is 47.3 $\mathrm{kJ} / \mathrm{mol}$, which is much lower than those for the first two processes. Thus, it is demonstrated that step 2, the rearrangement of the Criegee intermediate, is the rate determining step for the BV oxidation of cyclohexanone catalyzed by TS- 1 zeolite.

It has been reported that Sn-beta catalyzed BV oxidation involves the preferential activation of the carbonyl group of cyclohexanone by using the tetrahedral $\mathrm{Sn}\left(\mathrm{OSiH}_{3}\right)_{3} \mathrm{OH}$ species as a Lewis acidic catalyst [32,34]. In order to demonstrate that TS-1 zeolite does not follow this reaction route, we performed DFT calculations on this hypothetical route (Fig. 3). We first studied the model that a cyclohexanone molecule is adsorbed at the Ti site (see R1 in Fig. 3). The distance between the Ti and $\mathrm{O}_{\text {c }}$ atoms is very long ( $3.58 \AA$ ), which indicates that there is no interaction between the $\mathrm{Ti}$ and the carbonyl group of cyclohexanone. However, there is a strong interaction between $\mathrm{O}_{\mathrm{c}}$ and the $\mathrm{Ti}-\mathrm{O}^{4} \mathrm{H}$ group (the $\mathrm{O}_{\mathrm{c}} \cdots \mathrm{H}$ length is $1.86 \AA$ ), which results in the low energy for the R1 complex $(-76.8 \mathrm{~kJ} / \mathrm{mol})$. Therefore, the cyclohexanone molecule was only adsorbed, but not activated at the Ti site. We also studied a model where both the cyclohexanone and $\mathrm{H}_{2} \mathrm{O}_{2}$ molecules are adsorbed simultaneously at the $\mathrm{Ti}$ site and via the $\mathrm{O}^{4}-\mathrm{H}$ group (see R2 in Fig. 3). The distances of $\mathrm{Ti} \cdots \mathrm{O}_{\mathrm{c}}, \mathrm{C}_{1} \cdots \mathrm{O}_{\mathrm{b}}$ and $\mathrm{C}_{2} \cdots \mathrm{O}_{\mathrm{b}}$ are $3.61,5.39$, and $5.44 \AA$ A respectively, which means that the cyclohexanone molecule is neither activated at the tetrahedral Ti active site nor adsorbed via $\mathrm{H}_{2} \mathrm{O}_{2}$ molecules. Furthermore, the formation reaction of the R2 complex is endothermic, and the corresponding energy is $46.9 \mathrm{~kJ} / \mathrm{mol}$. From the above calculations, we believe that TS-1 catalyzed BV oxidation does not follow this reaction pathway. Thus, BV oxidation of cyclohexanone catalyzed by TS-1 has a different mechanism to that catalyzed by Sn-beta.

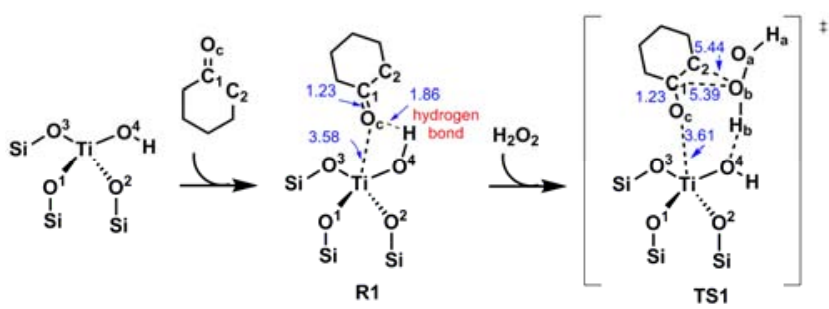

Fig. 3. Hypothetical reaction pathway of cyclohexanone BV oxidation catalyzed by TS-1 zeolite involving the preferential activation of the carbonyl group of the cyclohexanone molecule.

\subsubsection{Reaction mechanism of the ring opening of} $\varepsilon$-carprolactone

$\varepsilon$-carprolactone molecules are unstable. Their 7-membered rings can be opened to form 6-hydroxyhexanoic acids by hydrolysis in the presence of water [38]. Two possible 0 positions in $\varepsilon$-carprolactone can be attacked by protons, as shown in Fig. 4. The protons are contributed by $\mathrm{H}_{2} \mathrm{O}_{2}$ or Ti-OOH species $[1,2]$. The energies required for a proton to attack the 0 atom in the carbonyl group and in the 7-membered ring are -1618.8 and $-1618.7 \mathrm{~kJ} / \mathrm{mol}$, respectively. According to the minimum energy principle, proton ions prefer to attack the 0 atom in the carbonyl group of $\varepsilon$-carprolactone. Furthermore, the charge of the $\mathrm{C}$ atom in the carbonyl group increases to 0.69 , which means that it can accept the nucleophilic attack of $\mathrm{H}_{2} \mathrm{O}$ molecules more easily. As a result, 6-hydroxyhexanoic acid molecules are produced by the pathway shown in Fig. $4[1,2,38]$.

\subsubsection{Catalytic reaction route of 6-hydroxyhexanoic acid}

With respect to 6-hydroxyhexanoic acid molecule, there is one alcoholic hydroxyl group in its terminal position, which can be oxidized in the $\mathrm{TS}-1 / \mathrm{H}_{2} \mathrm{O}_{2} / \mathrm{H}_{2} \mathrm{O}$ system as reported in the literature [39]. Thus, it is likely that 6-hydroxyhexanoic acid is oxidized to produce adipic acid by the route illustrated in Fig. 5. As previously mentioned, $\mathrm{H}_{2} \mathrm{O}_{2}$ molecules can react with $\mathrm{Ti}-\mathrm{OH}$ groups, forming highly oxidative Ti-OOH species. Meanwhile, 6-hydroxyhexanoic acid can be oxidized by the Ti-OOH species to produce 6-aldehyde caproic acid. Since 6-aldehyde caproic acid is very active in this condition, it is simultaneously transformed to adipic acid by oxidation with the participation of Ti-OOH species [56-58]. The detailed reaction mechanism of this reaction will be investigated in the future.

\subsection{Catalytic performance of HTS-1 zeolite in the oxidation of cyclohexanone}

In order to demonstrate the catalytic performance of HTS-1 zeolite in cyclohexanone oxidation and verify the proposed reaction mechanism, a series of catalytic experiments were carried out with different solvents and reaction temperatures. The details of the experimental conditions and results are listed in Table 3. As illustrated in Fig. 6, several different reactions can occur during cyclohexanone oxidation, namely BV oxidation, hydroxylation, epoxidation, hydrolysis and alcohol oxida-

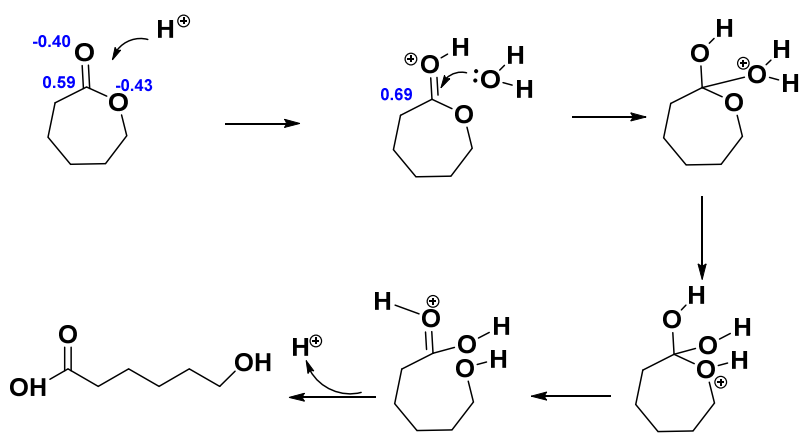

Fig. 4. Mechanism of ring opening reaction of $\varepsilon$-carprolactone catalyzed by Brönsted acid species in aqueous $\mathrm{H}_{2} \mathrm{O}_{2}$ solution. 


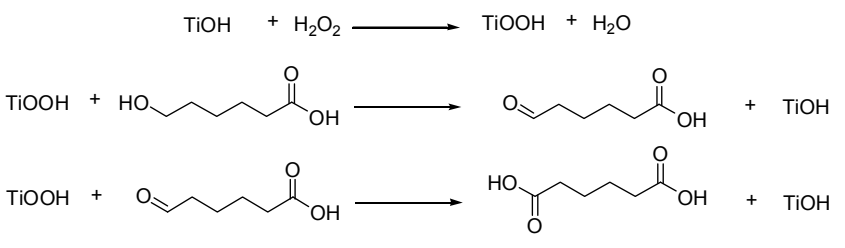

Fig. 5. Oxidation route of 6-hydroxyhexanoic acid catalyzed by TS-1 zeolite involving the activation of $\mathrm{H}_{2} \mathrm{O}_{2}$ molecule.

tion, leading to the formation of a number of organic products. We found that $\varepsilon$-carprolactone, 6-hydroxyhexanoic acid and adipic acid were the major products, which support the proposed reaction mechanisms. From the GC analysis, the overall catalytic network can be understood as the following: (1) $\varepsilon$-carprolactone is synthesized by the HTS-1 catalyzed BV oxidation of cyclohexanone, (2) $\varepsilon$-carprolactone is hydrolyzed to 6-hydroxyhexanoic acid, (3) the alcoholic hydroxyl groups in 6-hydroxyhexanoic acid are further oxidized to form adipic acid; (4) through hydroxylation and dehydrogenation, a small amount of side products can also be formed. From the application point of view, $\varepsilon$-carprolactone, 6-hydroxyhexanoic acid and adipic acid are very useful chemical intermediates for preparing different organic polymeric materials. The HTS-1 zeolite catalyzed cyclohexanone oxidation demonstrates the possibility of a "one-pot" reaction route to produce value added products from cyclohexanone.

Furthermore, we noticed that the reaction pathway catalyzed by HTS-1 zeolite was different from that of Sn-beta zeolite reported by Corma and coworkers. Sn-beta showed very high selectivity to lactone in the BV oxidation of cyclohexanone (over 98\%) [22]. This is because ketone oxidation catalyzed by Sn-beta zeolite involves the activation of the carbonyl group of cyclohexanone without enhancing the nucleophilic attacking capability of $\mathrm{H}_{2} \mathrm{O}_{2}$ [14]. It is worth noting that a large amount of organic solvent, such as methyl $t$-butyl ether (MTBE) or dioxane, which can prevent the hydrolysis of $\varepsilon$-carprolactone $[22,38]$, was introduced into the Sn-beta zeolite catalyzed oxidation process. This would incur high energy consumption for separating the products from the solvent.

In entries 1-3 in Table 3, the effect of the solvent was studied. Catalytic reactions without an organic solvent and in the presence of acetone or methanol were carried out. In all three

Table 3

Catalytic performance of HTS- $1^{\text {a }}$ zeolite in the cyclohexanone Baeyer-Villiger oxidation and comparison to that of Sn-Beta ${ }^{\text {b }}$.

\begin{tabular}{|c|c|c|c|c|c|c|c|c|c|}
\hline \multirow[b]{2}{*}{ Entry } & \multirow[b]{2}{*}{ Catalyst } & \multicolumn{3}{|c|}{ Reaction condition } & \multirow[b]{2}{*}{$\begin{array}{l}\text { Conversion } \\
\text { (\%) }\end{array}$} & \multicolumn{4}{|c|}{ Target product selectivity (\%) } \\
\hline & & Solvent & $\begin{array}{c}\text { Temp. } \\
\left({ }^{\circ} \mathrm{C}\right)\end{array}$ & $\begin{array}{l}\text { Time } \\
\text { (h) }\end{array}$ & & $\sum_{\text {Cyclohexanone }}^{110}$ & 6-hydroxyhexanoic acid & Adipic acid & Total \\
\hline$\overline{1}$ & HTS-1 & - & 70 & 4 & 18 & 16 & 24 & 22 & 62 \\
\hline 2 & HTS-1 & Acetone & 70 & 4 & 16 & 22 & 16 & 22 & 61 \\
\hline 3 & HTS-1 & Methanol & 70 & 4 & 15 & 8 & 35 & 8 & 51 \\
\hline 4 & HTS-1 & - & 90 & 8 & 60 & 1 & 61 & 28 & 90 \\
\hline 5 & HTS-1 & - & 80 & 8 & 53 & 1 & 54 & 33 & 88 \\
\hline 6 & HTS-1 & - & 70 & 8 & 30 & 10 & 43 & 21 & 74 \\
\hline 7 & HTS-1 & - & 60 & 8 & 24 & 13 & 42 & 19 & 74 \\
\hline 8 & Sn-beta & MTBE/dioxan & 90 & 3 & 52 & $>98$ & - & - & $>98$ \\
\hline
\end{tabular}

a The molar ratio of cyclohexanone to $\mathrm{H}_{2} \mathrm{O}_{2}$ in catalytic test of HTS- 1 zeolites is 1:1; amount of HTS-1 zeolite catalyst is 5 wt $\%$ of the total substrate. The molar ratio of solvent to cyclohexanone is 1:1 when a solvent is used. The reactions are carried out in a three phase (solid catalyst and two immiscible water/organic phases) condition.

b Catalytic data of Sn-beta zeolite in the cyclohexanone Baeyer-Villiger oxidation taken from Ref. [22]. The molar ratio of cyclohexanone to $\mathrm{H}_{2} \mathrm{O}_{2}$ is 1.5 : 1 ; the ratio of solvent to cyclohexanone is 20 or 30 by weight. The amount of Sn-Beta zeolite catalyst is $1.5 \mathrm{wt} \%$.

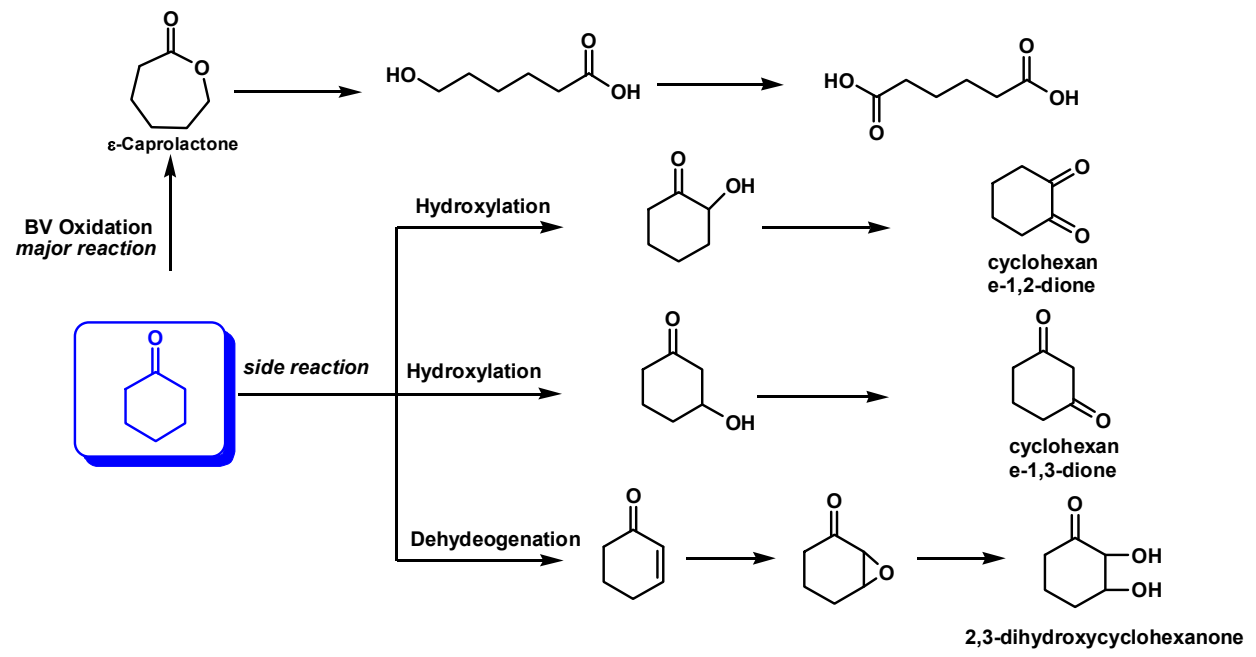

Fig. 6. Reaction network of oxidation of cyclohexanone catalyzed by HTS-1 zeolite 
cases, the three major high value products, namely $\varepsilon$-carprolactone, 6-hydroxyhexanoic acid and adipic acid, were produced. These results agreed well with our proposed reaction mechanisms. The cyclohexanone conversion and total target product selectivity were sensitive to reaction temperature (Table 3, entries 4-7). High temperature was preferred for the HTS-1 catalyzed cyclohexanone oxidation reactions. The optimized reaction temperature was $90{ }^{\circ} \mathrm{C}$, which gave a maximum cyclohexanone conversion of $60 \%, 90 \%$ selectivity of total production of $\varepsilon$-carprolactone, 6-hydroxyhexanoic acid and adipic acid molecules, and $79 \% \mathrm{H}_{2} \mathrm{O}_{2}$ efficiency.

It is believed that at high temperature, both the BV oxidation and ring opening reaction are enhanced. Meanwhile, the reaction rate of alcoholic oxidation of 6-hydroxyhexanoic acid was less affected by temperature. As a consequence, it is expected that the production of both $\varepsilon$-carprolactone and 6-hydroxyhexanoic acid would be increased at higher temperature. However, due to the enhanced ring opening reaction, $\varepsilon$-carprolactone is converted into 6-hydroxyhexanoic acid more rapidly at higher temperature (above $80^{\circ} \mathrm{C}$ ), resulting in very low $\varepsilon$-carprolactone production, which is shown as entries 4 and 5 in Table 3 . The results of the HTS-1 catalyzed cyclohexanone oxidation experiments supported our proposed mechanisms. The potential of an efficient "one-pot" industrial route of cyclohexanone oxidation for producing $\varepsilon$-carprolactone, 6-hydroxyhexanoic acid and adipic acid has been demonstrated. More important is that without using an organic solvent, the energy consumption for separation and purification is reduced. By using HTS-1 zeolite as the catalyst, no organic solvent is required to achieve high catalytic performance and selectivity.

\section{Conclusions}

DFT calculations were used to deduce the reaction mechanism of TS- 1 catalyzed BV oxidation of cyclohexanone. $\mathrm{H}_{2} \mathrm{O}_{2}$ molecules are adsorbed and activated at a $\mathrm{Ti}$ active site by the interaction between the Ti species and the $\mathrm{O}$ atoms of $\mathrm{H}_{2} \mathrm{O}_{2}$. The activation of the $\mathrm{H}_{2} \mathrm{O}_{2}$ molecule accelerates both BV oxidation and alcoholic oxidation, with the formation of $\varepsilon$-carprolactone and adipic acid, respectively. The mechanism was verified by experiments using HTS-1 as the catalyst, which demonstrated that $\varepsilon$-carprolactone, 6-hydroxyhexanoic acid and adipic acid were the major products of this "one-pot" reaction. The experimental results showed that a high reaction temperature $\left(90^{\circ} \mathrm{C}\right)$ favored cyclohexanone conversion and the selectivity of the targeted products. Under the optimized conditions, the cyclohexanone conversion was $60 \%$, and the total selectivity of target products was $90 \%$.

\section{References}

[1] Jiménez-Sanchidrián C, Ruiz J R. Tetrahedron, 2008, 64: 2011

[2] ten Brink G J, Arends I W C E, Sheldon R A. Chem Rev, 2004, 104: 4105

[3] Krow G R. Org React, 1993, 43: 251

[4] Strukul G. Angew Chem Int Ed , 1998, 37: 1199

[5] Kotlewska A J, van Rantwijk F, Sheldon R A, Arends I W C E. Green
Chem, 2011, 13: 2154

[6] Figg T M, Webb J R, Cundari T R, Gunnoe T B. J Am Chem Soc, 2012, 134: 2332

[7] Renz M, Meunier B. Eur JOrg Chem, 1999: 737

[8] Bolm C, Schlingloff G, Weickhardt K. Angew Chem, 1994, 106: 1944

[9] Watanabe A, Uchida T, Ito K, Katsuki T. Tetrahedron Lett, 2002, 43: 4481

[10] Punniyamurthy T, Velusamy S, Iqbal J. Chem Rev, 2005, 105: 2329

[11] Fischer J, Hölderich W F. Appl Catal A, 1999, 180: 435

[12] von Baeyer A, Seyffert O. Ber Deut Chem Gesell, 1899, 32: 3619

[13] Pande C S, Jain N. Synth Commun, 1989, 19: 1271

[14] Renz M, Blasco T, Corma A, Fornés V, Jensen R, Nemeth L. Chem EurJ, 2002, 8: 4708

[15] Strukul G, Varagnolo A, Pinna F. J Mol Catal A , 1997, 117: 413

[16] Corma A, Navarro M T, Renz M. J Catal, 2003, 219: 242

[17] Koch S S C, Chamberlin A R. Synth Commun, 1989, 19: 829

[18] Bernini R, Coratti A, Fabrizi G, Goggiamani A. Tetrahedron Lett, 2003, 44: 8991

[19] Kaneda K, Yamashita T. Tetrahedron Lett, 1996, 37: 4555

[20] Kaneda K, Ueno S, Imanaka T. J Chem Soc, Chem Commun, 1994: 797

[21] Pillai U R, Sahle-Demessie E. J Mol Catal A, 2003, 191: 93

[22] Corma A, Nemeth L T, Renz M, Valencia S. Nature, 2001, 412: 423

[23] Lei Z Q Zhang Q H, Luo J J, He X Y. Tetrahedron Lett, 2005, 46: 3505

[24] Ueno S, Ebitani K, Ookubo A, Kaneda K. Appl Surf Sci, 1997, 121: 366

[25] Kawabata T, Ohishi Y, Itsuki S, Fujisaki N, Shishido T, Takaki K, Zhang Q H, Wang Y, Takehira K.J Mol Catal A, 2005, 236: 99

[26] Lei Z Q, Ma G F, Jia C G. Catal Commun, 2007, 8: 305

[27] Raja R, Thomas J M, Sankar G. Chem Commun, 1999: 525

[28] Rafelt J S, Clark J H. Catal Today, 2000, 57: 33

[29] Boronat M, Concepción P, Corma A, Renz M. Catal Today, 2007, 121: 39

[30] Corma A, Renz M. Chem Commun, 2004, (5): 550

[31] Boronat M, Corma A, Renz M. J Phys Chem B, 2006, 110: 21168

[32] Wang Z B, Mizusaki T, Sano T, Kawakami Y. Bull Chem Soc Jpn, 1997, 70: 2567

[33] Xia C J, Lin M, Zhu B, Shu X T. Chin Petrol Proc \& Petrochem Technol, 2012, 14: 7

[34] Xia C J, Zhu B, Lin M, Shu X T. Chin Petrol Proc \& Petrochem Technol, 2012, 14: 33

[35] Peris G, Miller S J. Org Lett, 2008, 10: 3049

[36] Thangaraj A, Eapena M J, Sivasankera S, Ratnasamy P. Zeolites, 1992, 12: 943

[37] Moliner M, Román-Leshkov Y, Davis M E. Proc Natl Acad Sci, 2010, 107: 6164

[38] Cavani F, Raabova K, Bigi F, Quarantelli C. Chem Eur J, 2010, 16: 12962

[39] Bonino F, Damin A, Ricchiardi G, Ricci M, Spano G, D'Aloisio R, Zecchina A, Lamberti C, Prestipino C, Bordiga S. J Phys Chem B, 2004, 108: 3573

[40] Bordiga S, Damin A, Bonino F, Ricchiardi G, Lamberti C, Zecchina A. Angew Chem Int Edt, 2002, 41: 4734

[41] Perego G, Taramasso M, Notari B. US Patent 4410501. 1983

[42] Munakata H, Oumi Y, Miyamoto A. J Phys Chem B, 2001, 105: 3493

[43] Wang Y R, Lin M, Tuel A. Microporous Mesoporous Mater, 2007, 102: 80

[44] Zheng A G, Xia C J, Xiang Y J, Xin M D, Zhu B, Lin M, Xu G T, Shu X T. Catal Commun, 2014, 45: 34

[45] Wang Y R, Tuel A. Microporous Mesoporous Mater, 2008, 113: 286

[46] Peregot G, Bellussi G, Corno C, Taramasso M, Buonomo F, Esposito 


\section{Graphical Abstract}

Chin. J. Catal., 2015, 36: 845-854 doi: 10.1016/S1872-2067(15)60859-2

\section{Heterogeneous oxidation of cyclohexanone catalyzed by TS-1: Combined experimental and DFT studies}

Changjiu Xia, Long Ju, Yi Zhao, Hongyi Xu, Bin Zhu, Feifei Gao, Min Lin*, Zhenyu Dai, Xiaodong Zou*, Xingtian Shu Stockholm University, Sweden; Research Institute of Petroleum Processing, China

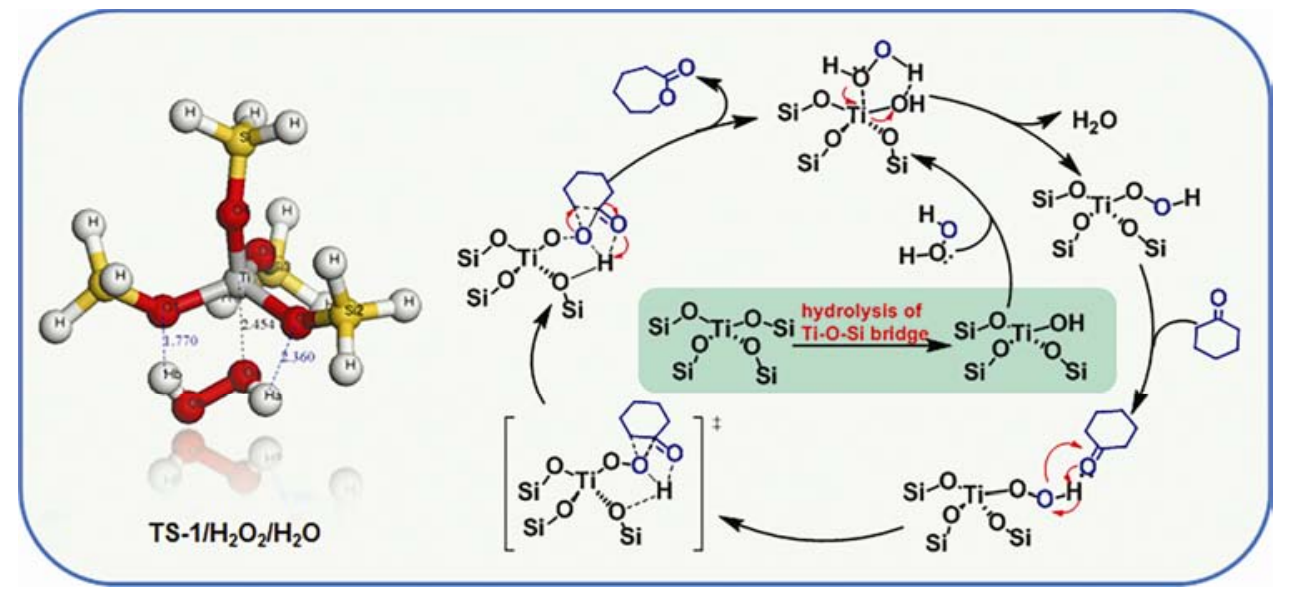

The mechanism of the oxidation of cyclohexanone catalyzed by titanium silicate zeolite using aqueous hydrogen peroxide as the oxidant was investigated by combining DFT calculations with catalytic experiments.

\section{A. Stud Surf Sci Catal, 1986, 28: 129}

[47] Corma A, Domine M E, Nemeth L, Valencia S. J Am Chem Soc, 2002, 124: 3194

[48] Roy S, Bakhmutsky K, Mahmoud E, Lobo R F, Gorte R J. ACS Catal, 2013, 3: 573

[49] Spanó E, Tabacchi G, Gamba A, Fois E. J Phys Chem B, 2006, 110: 21651

[50] Bordiga S, Bonino F, Damin A, Lamberti C. Phys Chem Chem Phys, 2007, 9: 4854

[51] Guo Q, Sun K J, Feng Z C, Li G N, Guo M L, Fan F T, Li C. Chem Eur J, 2012, 18: 13854
[52] Bhaumik A, Kumar P, Kumar R. Catal Lett, 1996, 40: 47

[53] Kumar R, Bhaumik A. Microporous Mesoporous Mater, 1998, 21: 497

[54] Kim M S, Seo K S, Khang G, Lee H B. Macromol Rapid Commun, 2005, 26: 643

[55] Dutta A, Pramanik M, Patra A K, Nandi M, Uyama H, Bhaumik A. Chem Commun, 2012, 48: 6738

[56] Thomas S M, DiCosimo R, Nagarajan V. Trends Biotechnol, 2002, 20: 238

[57] Usui Y, Sato K. Green Chem, 2003, 5: 373

[58] Labet M, Thielemans W. Chem Soc Rev, 2009, 38: 3484

\section{Supporting Information}

- Structural, physicochemical and surface properties of HTS-1 zeolite

The structural information, physicochemical and surface properties of TS-1 and HTS-1 were investigated by various techniques. X-ray fluorescence analysis (XRF) was made on a Rigaku 3271E X-ray fluorescence spectrometer with semi-quantitative analysis system. X-ray powder diffraction (XPRD) patterns were collected on a Bruker (Siemens) D5005 diffractometer using nickel filtered $\mathrm{Cu} K_{\alpha}$ radiation $(\lambda=$ $0.15418 \mathrm{~nm}$ ) under ambient conditions in the $2 \theta$ range of $5^{\circ}-35^{\circ}$ with a step size of $0.02^{\circ}$ and exposure time of $1 \mathrm{~s}$ per step. $\mathrm{N}_{2}$ adsorption-desorption isotherms were collected at $-196{ }^{\circ} \mathrm{C}$ using a Micromeretics ASAP 2010 apparatus. Before the measurement, about $50 \mathrm{mg}$ of the sample was dehydrated under vacuum (10-3 Torr) at $300{ }^{\circ} \mathrm{C}$ overnight. The specific surface areas were determined from the linear part of the BET equation. TEM was carried out on a FEI G2 F20S-TWIN electron microscope.

Fourier transform infrared spectra (FT-IR) were recorded on a Nicolet 8210 infrared spectrometer in the range from 400 to $4000 \mathrm{~cm}^{-1}$. ${ }^{29} \mathrm{Si}$ solid-state Nuclear Magnetic Resonance (NMR) experiments were performed with magic angle spinning (MAS) on an Inanity Plus-400 spectrometer. Samples were spun at $10 \mathrm{kHz}$ in $4 \mathrm{~mm}$ zirconium rotors. A classical cross-polarization sequence was used with 2 ms contact time and a recycle delay of $10 \mathrm{~s}$. The diffuse reflectance ultraviolet-visible (DR UV-Vis) spectrum was obtained on a Perkin-Elmer Lambda $20 \mathrm{UV}$-visible spectrometer in the range of 200-800 $\mathrm{cm}^{-1}$. X-ray photoemission spectroscopy (XPS) was carried out on a PHI model 590 spectrometer with Al K $\alpha$ radiation source. 
Table S1

XRF results, textural properties and crystallinity of TS- 1 and HTS-1 samples.

\begin{tabular}{lcccccccc}
\hline Sample & \multicolumn{2}{l}{$\begin{array}{c}\text { XRF analysis } \\
\text { (wt } \%)\end{array}$} & \multicolumn{2}{c}{$\begin{array}{c}\text { BET surface } \\
\text { area }\left(\mathrm{m}^{2} / \mathrm{g}\right)\end{array}$} & \multicolumn{2}{c}{$\begin{array}{c}\text { Pore volume } \\
\left(\mathrm{cm}^{3} / \mathrm{g}\right)\end{array}$} & \multirow{2}{*}{$\begin{array}{c}\text { Relative } \\
\text { crystallinity }\end{array}$} \\
\cline { 2 - 7 } & $\mathrm{SiO}_{2}$ & $\mathrm{TiO}_{2}$ & $S_{\text {BET }}$ & $S_{\mathrm{Z}}$ & $S_{\mathrm{M}}$ & $V_{\text {micro }}$ & $V_{\text {meso }}$ & $(\%)$ \\
\hline TS-1 & 92.89 & 7.11 & 441 & 402 & 39 & 0.186 & 0.085 & 98 \\
HTS-1 & 92.39 & 7.61 & 428 & 383 & 45 & 0.172 & 0.160 & 100
\end{tabular}

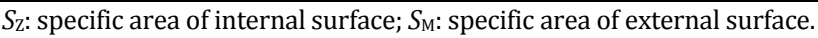

The results of XRF analysis of both TS- 1 and HTS- 1 are summarized in Table S1. Both samples consist of $\mathrm{SiO}_{2}$ and $\mathrm{TiO}_{2}$, with similar $\mathrm{SiO}_{2} / \mathrm{TiO}_{2}$ ratios, demonstrating that the dissolution-recrystallization process of TS-1 has no significant effects on its composition. Fig. S1 shows XRPD patterns of TS- 1 and HTS-1, which correspond to that of a typical MFI-type zeolite [1]. The relative crystallinity of both TS-1 and HTS-1 is high (Table S1), as calculated using the method described in Ref. [2].

TEM shows the presence of large amount of mesopores in the HTS- 1 sample compared to the TS-1 sample (Fig. S2). This indicates that the post-treatment of TS-1 has an impact on the mesoporpous structure. Fig. S3 shows the $\mathrm{N}_{2}$ adsorption-desorption isotherm of HTS-1. It is observed that the isotherm at $p / p_{0}=0.4-1.0$ exhibits hysteresis and is of the Type IV isotherm caused by mesopores [3]. The BET surface areas and pore volumes of TS-1 and HTS- 1 are summarized in Table S1. Although the BET surface area of HTS-1 and the micropore volume are slightly smaller than those of TS-1, the mesopore volume of HTS-1 is significantly larger than that of TS- 1 .

The framework tetrahedral Ti (IV) species of TS-1 are con-

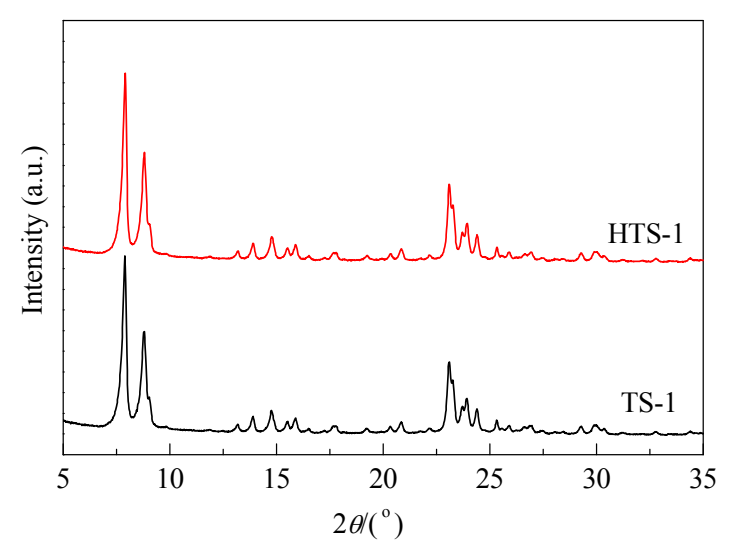

Fig. S1. XRPD patterns of TS-1 and HTS-1 samples.

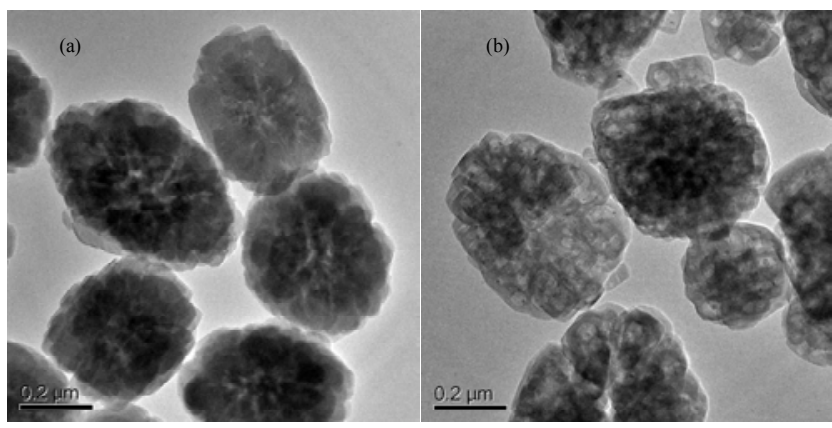

Fig. S2. TEM images of TS-1 and HTS-1. (a) TS-1; (b) HTS-1.

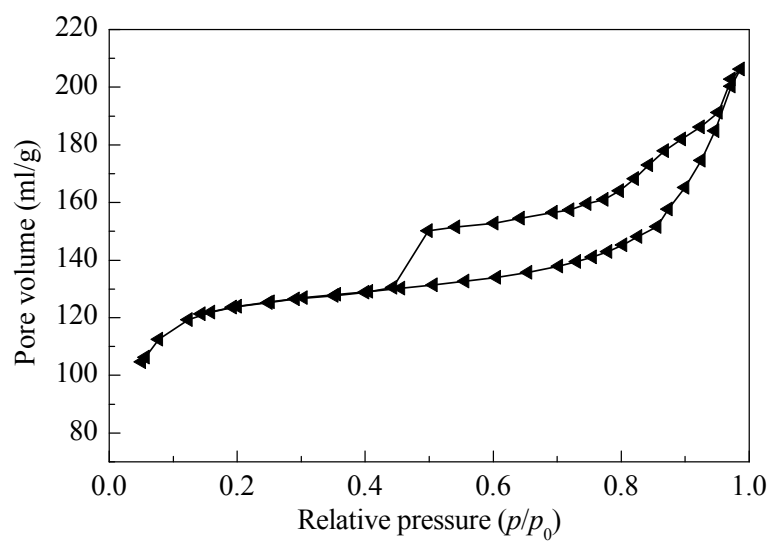

Fig. S3. $\mathrm{N}_{2}$ adsorption/desorption isotherm of HTS-1.

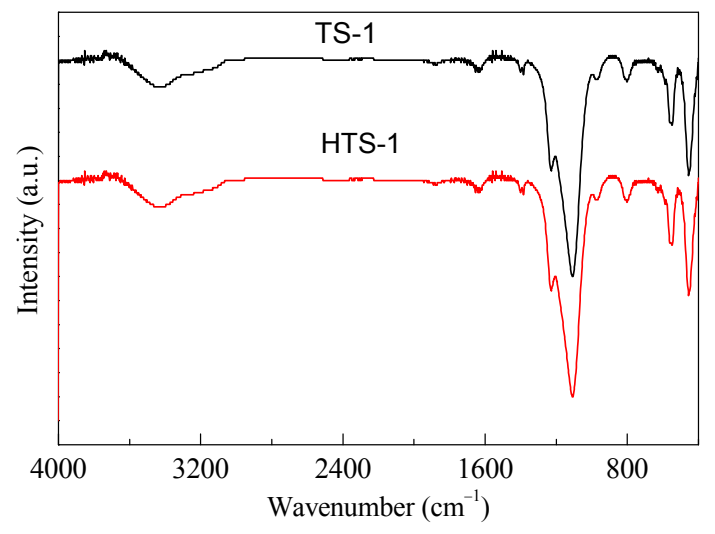

Fig. S4. FT-IR spectra of TS-1 and HTS-1.

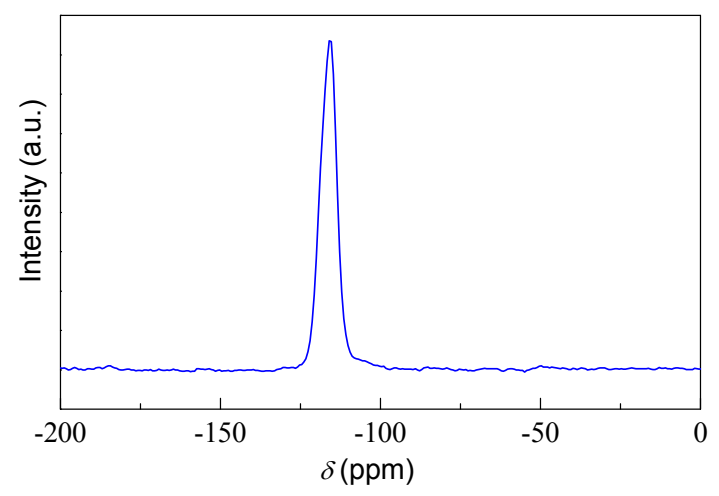

Fig. S5. ${ }^{29}$ Si MAS NMR spectrum of HTS-1.

sidered as the active sites for catalytic oxidation of organic compounds [4]. In order to investigate the structural environment of Ti species in HTS-1, FT-IR, ${ }^{29}$ Si MAS NMR, XPS and DR UV-Vis spectroscopy were conducted, as shown in Figs. S4-S7.

${ }^{29} \mathrm{Si}$ MAS NMR of HTS-1 shows only one main peak at -114.1 ppm corresponding to $\mathrm{Q}^{4}$ (Fig. S5) [5]. This indicates that there is very little $\mathrm{Si}-\mathrm{OH}$ group in the sample.

XPS provides information about the chemical composition and chemical state of titanium in the surface region (Fig. S6) [6,7]. The Ti/Si atomic ratio estimated by XPS is $0.25 / 24.74$ (or 1.00/98.68), which is evidently much lower than that (7.61/92.39) obtained by XRF analysis. This indicates that Ti is 

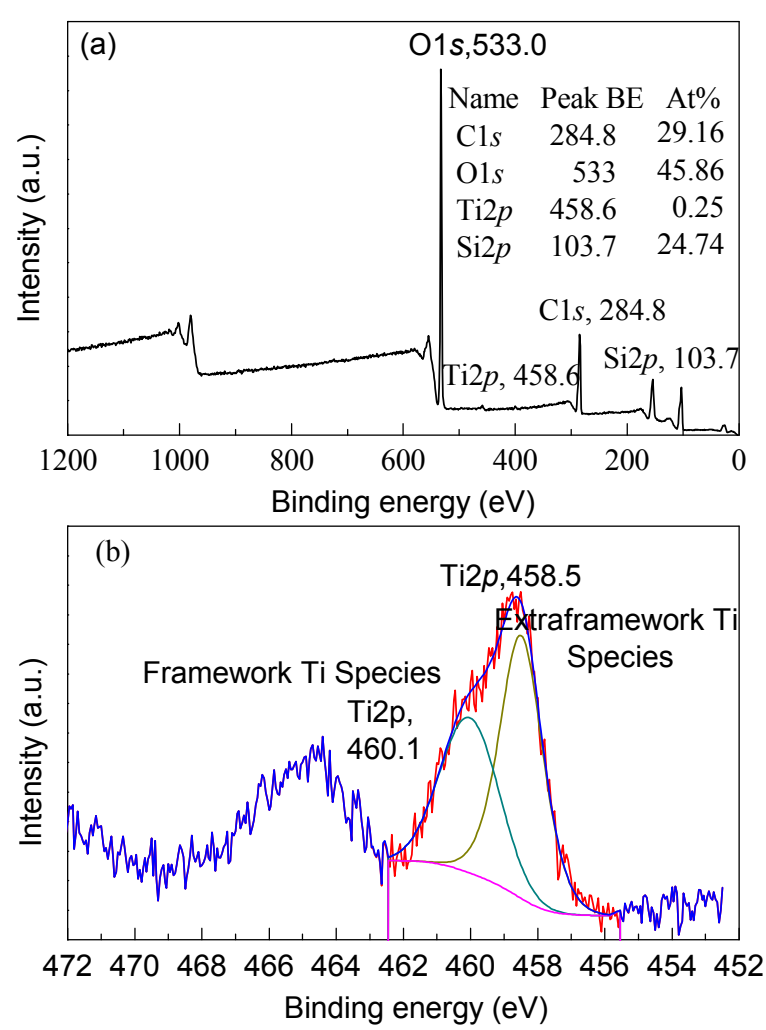

Fig. S6. The XPS spectra of HTS-1. (a) the survey XPS spectrum; (b) the Ti2 $p$ XPS spectrum.

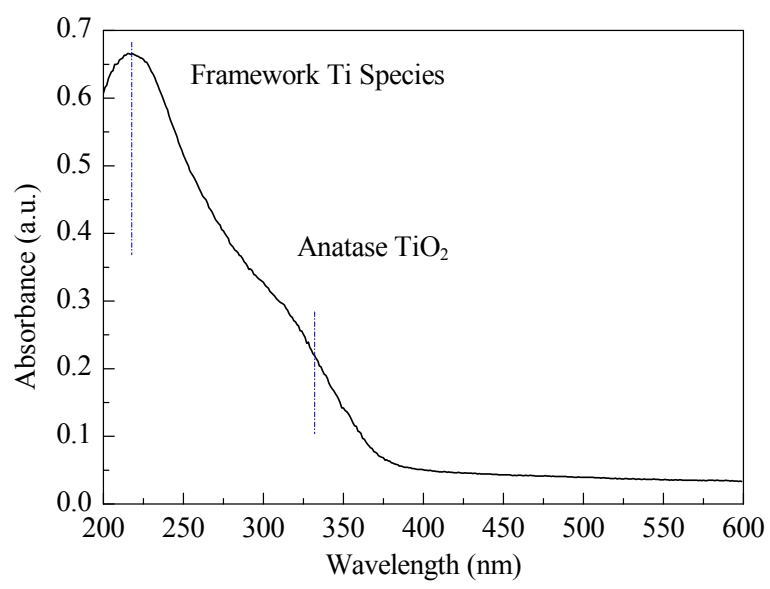

Fig. S7. UV-Vis spectrum of HTS-1.

preferably distributed within the bulk than on the surface of the HTS-1 sample. The two peaks at 460.1 and $458.5 \mathrm{eV}$ (Fig. S6(b)) correspond to framework tetrahedral Ti(IV) and extra-framework octahedral Ti(IV), respectively [8]. The DR UV-vis spectrum of HTS-1 exhibits two bands at 210 and 350 nm (Fig. S7), which can be assigned to oxygen-tetrahedral Ti(IV) and oxygen-octahedral Ti(IV), respectively [9]. This also agrees to the results obtained by XPS.

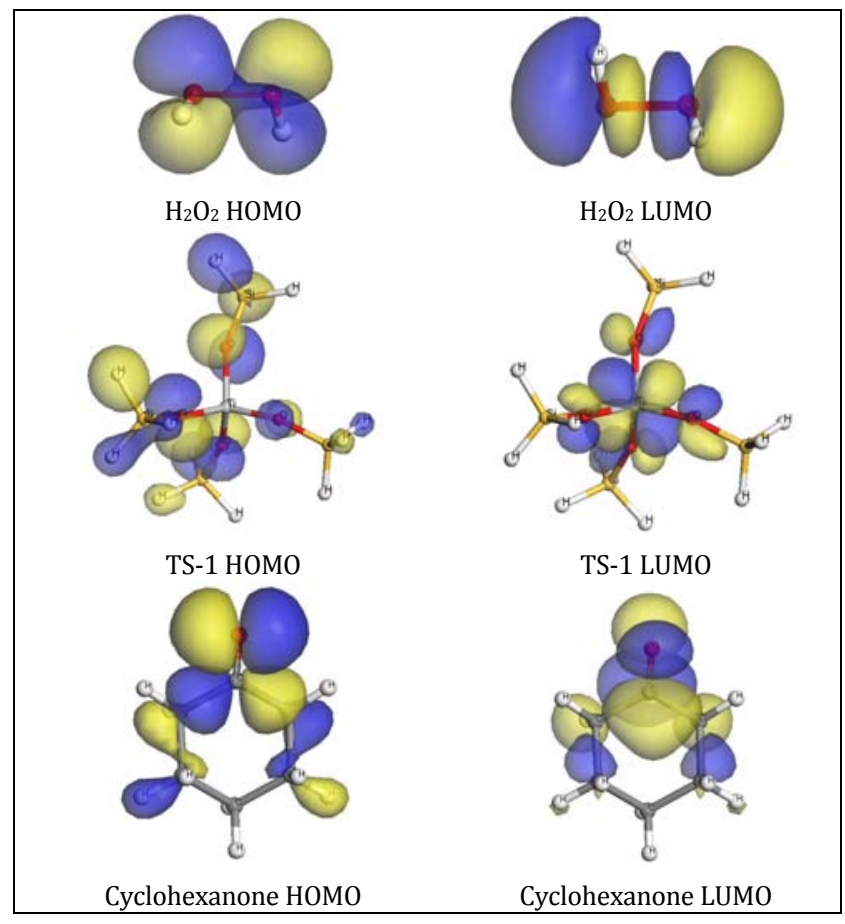

Fig. S8. Orbital iso-surfaces of $\mathrm{H}_{2} \mathrm{O}_{2}, \mathrm{Ti}\left(\mathrm{OSiH}_{3}\right) \mathrm{OH}$ and cyclohexanone molecules.

- The relevant orbital iso-surfaces

The orbital iso-surfaces of $\mathrm{H}_{2} \mathrm{O}_{2}, \mathrm{Ti}\left(\mathrm{OSiH}_{3}\right) \mathrm{OH}$ and cyclohexanone molecules are shown in Fig. S8. There is no HOMO in the tetrahedral $\mathrm{Ti}$ active site, which means the Ti species can only coordinate with electron-rich functional groups by the acceptor-donator interaction between the LUMO of TS- 1 and the $\mathrm{HOMO}$ of $\mathrm{O}$ atoms in the $\mathrm{H}_{2} \mathrm{O}_{2}$ and cyclohexanone molecules.

\section{References}

[1] Thangaraj A, Eapena M J, Sivasankera S, Ratnasamy P. Zeolites, 1992, 12: 943

[2] ASTM D5758-01(2007) e-1 Standard Test Method for Determination of Relative Crystallinity of Zeolite ZSM- 5 by X-Ray Diffraction, http://www.astm.org/Standards/D5758.htm.

[3] Somorjai G A, Li Y. Introduction to Surface Chemistry and Catalysis, New York: Wiley, 2010. 54

[4] Tozzola G, Mantegazza M A, Ranghino G, Petrini G, Bordiga S, Ricchiardi G, Lamberti C, Zulian R, Zecchina A.J Catal, 1998, 179: 64

[5] Thangaraj A, Sivasanker S. J Chem Soc, Chem Commun, 1992: 123

[6] Stöcker M. Microporous Mater, 1996, 6: 235

[7] Langerame F, Salvi A M, Silletti M, Moretti G. Surf Interf Anal, 2008, 40: 695

[8] Moretti G, Salvi A M, Guascito M R, Langerame F. Surf Interf Anal, 2004, 36: 1402

[9] Borin M F, da Silva T, Felisbino R F, Cardoso D. J Phys Chem B, 2006, 110: 15080 